\title{
Media Exposure to Thai Cultural Universals in Myanmar
}

\author{
By Kanchana Chokriensukchai*
}

\begin{abstract}
Cultural universals can be used to communicate in order to create awareness about tourism. This study applies to the conceptual framework of George Murdock (1945), which is a group of cultural universals that appears in every society. The previous study had found nine Thai cultures that were cultural universals. It meant that nine Thai cultural universals inevitably appear in all nations as well. Creating a Thai cultural universal with international recognition would be easier especially for those familiar with Asian culture, including Myanmar. One of the findings of the survey is that the majority of Myanmar citizens travel to other countries at least once or twice annually with family or friends. Nature was found to be one of the main attractions. It was also revealed that the people of Myanmar sought other interest areas by approaching other people who had already been to the places. While the majority had never visited Thailand, they had gained knowledge about the country through personal media. They also expressed that if they had the opportunity to visit neighboring countries they would opt for Thailand. Thai food emerged as the Thai cultural universal that could boost Myanmar tourism. Amongst other Thai cultural universal activities, most of them said they wanted to attend short courses in university or school followed by study or training for a career. The outcome indicates that personal media may be the main way of promoting Thai tourism in Myanmar. The content should focus on Thai food and short courses in school or university or career training.
\end{abstract}

Keywords: communication, media, tourism culture, Thai cultural universal, Myanmar

\section{Introduction}

Tourism plays an important role in the world's economy, even more so when the world is in recovery following a global economic recession. Tourism, can attract foreign currency, enabling local people to earn a living. However, noteworthy about the growth characteristics of tourism can bring about the world's gross domestic product (GDP) and the percent is even higher in developing countries, including Thailand, where tourism is a key component of the economic sector.

"In 2015, Thailand has direct contribution of Tourism to GDP was THB1,247.3bn (9.3\% of GDP).This primarily reflects the economic activity generated by industries such as hotels, travel agents, airlines and other passenger transportation services (excluding commuter services). it also includes, for example, the activities of the restaurant and leisure industries directly supported The direct contribution of Travel \& Tourism

\footnotetext{
* Associate Professor, Department of Radio and Television Broadcasting, The University of the Thai Chamber of Commerce, Thailand.
} 
to GDP is expected to grow by $6.7 \%$ pa to THB2,482.9bn (14.0\% of GDP) by $2026 . "$

(WTTC, 2016).

The growth of the tourist industry is not only occurring in Thailand, but also among other countries in Asia, such as China and India, and countries in the Middle East. Competing in the global market, many countries have introduced aggressive policies and strategies that aim at promoting domestic tourism through advertising and public relations.

"Cultural tourism has therefore been embraced globally by local, national, and transnational bodies. UNESCO promotes cultural tourism as a means of preserving world heritage, the European Commission supports cultural tourism as a major industry, and the newly emerging nation-states of Africa and Central Europe see it as a support for national identity. In many parts of the world it has become a vital means of economic support for traditional activities and local creativity"

(Richards, 2011:1).

As each strategy used to attract tourists will impact Thailand, it is important for Thailand to formulate a clear strategy for attracting new tourism. In comparison to other countries, travel in Thailand is affordable. This could be a source of attraction for neighboring countries and those in the Asia Pacific region that have easy access and fall within a lower budget category.

\section{Culture and Tourism}

The relationship between culture and economy has undergone an important shift in focus, from the mere conservation of culture to its economic enhancement, which reveals the links among culture, society, and economic development (Alberti and Giusti, 2012; Cooke and Lazzeretti, 2008; Lazzeretti, Capone and Cinti 2011; Power and Scott, 2004; Rabaneda, 2012). There are numerous benefits coming from the relationship between culture and tourism, since cultural resources are very often potential for attracting tourists. Cultural heritage makes cities distinctive and unique, and therefore different than others on the wide tourism market.

"Cultural tourism has become increasingly politicized as governments weigh up the advantages and disadvantages of this potentially lucrative industry, often viewing it as their sole economic option if they wish to compete in the global arena. The environmental and socio-cultural consequences of such decisions are often overlooked; hence it falls to the communities themselves to protect their own interests, usually with inadequate political support"

(Smith, 2009:11). 
Culture is the characteristics and knowledge of a particular group of people, defined by everything from language, religion, cuisine, social habits, music and arts. On the other hand, culture provides distinct identity to cities, which in turn generates opportunities for drawing attention to and interest in experiencing and learning. Since ancient times, people have found local cultures of travel destinations attractive; tourism focusing on cultural experiences is now given the name 'cultural tourism' and has (re) flourished in many places. Cultural tourism is the movement of persons to specific cultural attractions, such as heritage sites, artistic and cultural manifestations, arts and drama outside their normal place of residence and this experience usually includes learning elements (Richards, 1996/2005: 24). On the one hand, it satisfies the needs of the visitors, and on the other, it is beneficial for the social development of local communities. Its impact on economy cannot be underestimated either when considering the fact that 30 million American travelers participating in cultural tourism have stayed longer at a destination (Mandala Research, 2013). An international visitor survey conducted in Bangkok in 2009 also suggests that culture has become one of the influential pull factors. The factors influencing the decision to visit Bangkok are often culturally relevant ones, such as Thai food, archaeological sites, traditional folk art, and friendly people, if not shopping centers (Bangkok University Research Center, 2009).

It is thus meaningful for effective tourism marketing strategies to include the cultural perspective. In particular, identifying 'cultural universals,' or cultural elements that attract international tourists in everyday settings, rather than special cultural artifacts appear more helpful in designing the strategy. This study, therefore, explores the perceptions of Myanmar residents on Thai cultural universals as a potential tourism product for the international market. These can be used for future discussions regarding strategic use of Thai cultural universals in tourism promotion.

\section{Tourism and Communication}

As in the general case of consumers' decision making process (e.g., Kotler and Armstrong, 2001), potential tourists go through stages prior to making a decision to travel: motivation - information search - image formation evaluation - decision-making. The first stage is 'motivation' where people perceive their needs. Push and pull factors work at this stage, and then people move to the next stage, seeking information about travel and potential destinations in order to check if taking a trip fulfills their needs. At the 'information searching' stage, the initially internal information search starts to acquire relevant information from one's own past experiences, memories, or knowledge. If the data collected in the internal search is not adequate for decision-making, people start to engage in an external information search, that is, obtaining information from various external sources (Fodness and Murray, 1999). With the information gathered, people form certain images of potential 
travel destinations, which will affect their 'evaluation' and 'decision-making' at the end.

Applying this consumer's decision-making process, images of destination shaped by internal and external information are crucial for considering tourism marketing. In particular, internal information will work as predispositions, or as filters, in an external information search, which means internal information is more important. Moreover, we often compare new things with what we know already, and accept something familiar and compatible with existing knowledge more easily (Rogers, 2003). It is therefore more effective to promote cultural products that are either familiar or comparable and compatible with visitors' existing knowledge or images.

\section{Cultural Universals as Pull Factors in Travel Decision Making}

Cultural universals are present in every society. Cultural universals as pull factors can be linked to push factors, which are awareness, attitude, and behavior. The concept of cultural universals is derived from the study of comparison in cultures by the anthropologist George Murdock who published "The Common Denominator of Cultures" in 1945. His article says the meaning of cultural universals is "culture that appears in every culture" or "appears in every human society." Sometimes the term 'cultural universals' is written as 'human universals.' Other scholars who have referenced Murdock's work regarding cultural universals include Levi-Strauss (1966), Spoehr (1965), a group of social science scholars from Universal of Cultures that included Cleaveland et al. (1979) and Brown (1991). These scholars commented that in cultural universals collected by Murdock, there is one type that is truly a cultural universal and can be found in every culture on the Earth. As noted, however, cultural universals may not exclusively fall into one of these conventional realms, and could include more crossover (Brown, 2004).

However, some societies might express these in different ways such as: inheritance rules; community; fire-maker; courtship; age-grading; dream interpretation; dancing; divination; cooking; government; bodily adornment; co-operative labor; faith healing; feasting; education; greetings; incest taboos; gift-giving; cleanliness training; athletic sports; games; folklore; family; cosmology; kin group; ethics; personal names; calendar; ethnobotany; eschatology; funeral rites; gestures; etiquette; division of labor; decorative art; organization; food taboo; and music. A developmental psychologist considers behaviors or attributes that appear in every culture as things that can be adapted in many situations. These can be used as contexts for making cognition by cultural universals for people who already have those experiences. Some believe that contexts can make them understand stories better than using different stories. This study is primarily concerned with how tourists' perception of cultural universals in Thailand influenced their travel choices. A 2009 survey of 474 subjects found that for foreigners fifteen years and above, the five most important environmental factors that influenced their travel 
choices in Bangkok included: Thai food, archaeological sites and artifacts, amicability, culture, traditional folk art, and shopping centers (Bangkok University Research Center, 2009). These fall within a group of already wellknown Thai cultural universals. However, there are Thai cultural universals that are not known, which need to be communicated with the goal of attracting more tourism. This implies that as in any other country, all people concerned need to know the content, characteristics of people, and the media they have access to in their countries, as well as the media exposure they have experienced.

In addition to the physical goods created as part of normal commercial activities, cultural products are part of a city's output. Cultural products derive from and are an expression of underlying values and beliefs of a particular culture. Historically, it was relatively easy to identify cultural products that were created by a specific culture.

Product development is a prerequisite for satisfying tourists' changing demands and ensuring the long-term profitability of the industry. Ideally, tourism products should meet marketplace demands, be produced costefficiently, and be based on the wise use of cultural and natural resources of the destination. Culture itself is able to stimulate demand for travel and many countries have taken this as a tourism product. Bringing what people are familiar with is easy to understand and could stimulate behavior easily. The concept of cultural familiarity can be explained by the concept of cultural universals.

Although cultural universals appear in every society, each society is different. For example, food is a cultural universal as everyone has to eat. However, Thai food is a cultural universal that is different and unique. Health treatment, also, is a cultural universal. However, treatment with medicinal herbs can be combined with faith in Buddhist beliefs. Thai cultural universals are unique and largely derived from its religion, which is unique and different from other religions. MacCannell (1999) and Cohen (1979:179-201) found that tourism and pilgrimage, or spiritual practice, are closely related. Therefore, Buddhist tradition can be used as an external force to pull people to make a travel decision as well. People who look for spiritual experiences can be called "spiritual tourists." Their journeys, or their spiritual interests, are explicitly concerned with moving closer to a religious setting. Also, spiritual tourists are often moving towards novelty or are experimenting with concepts and practices. Thus, the destination of a meditation retreat may be approached for recreational purposes, as a diversion from ordinary life, to have new experiences, to search or experiment with other religious beliefs and ways of being, or to travel to the religious setting the individual feels is their centre.

In cultural tourism, the product to be consumed will be culture. Culture is a complex concept and there are many definitions. Littrell (1997) sorts it into three categories: what people think (attitude, beliefs, ideas and values), what people do (normative behavior, pattern or way of life), and what people make (art work, artifacts, cultural products). What people make that is 'culture as product' is usually a traditional tourism product. Obvious examples of this are 
cultural heritage sites, many of which are listed by UNESCO, such as the Taj Mahal (India), the Great Wall (China), Mont-Saint-Michel (France), the Acropolis (Greece), or the Colosseum (Italy). However, what people do and think can also be transformed into tourism products, despite its often intangible form of 'culture as process.' Besides, local cultures in people's everyday life have been often overlooked and their values went unnoticed as they are regarded as universal and thus nothing special.

One cultural element particularly closely related to tourism has been pilgrimage, religious and/or spiritual practice (e.g., Cohen, 1979; MacCannell, 1999), including the ground tour to Mecca for Muslims, walking Camino de Santiago for Catholics, and Ise-Mairi for Japanese. Churches, temples and shrines have become a drive (push and pull forces) for many believers to travel. On the other hand, spiritual tourists are not limited to such believers. Some are interested in learning about other cultures through experiencing religious activities or visiting religious sites; others are interested in luck and superstition mostly as a new type of entertainment. Whether they see the experience as a learning opportunity or as entertainment, such cultural tourism can exist because people understand what religion means and can compare their own with others to find similarities and differences, which may bring curiosity and attraction.

Cultural universals are found across cultures, yet they vary in the style of output in each culture. In other words, cultural universals are 'etic' elements, though these include 'emic' elements simultaneously when culturally represented in a society. ${ }^{1}$ For instance, cooking is an etic fact, though local specialty dishes such as Thai cuisine are an emic fact. Similarly, health treatment itself is etic, but treatment using specific medicine or herbs with specific religious beliefs is emic. Religion, as mentioned above, is another example. The emic side of cultural universals is what makes the cultures of the travel destinations special and unique, and thus what appeals to visitors.

\section{Cultural Similarities}

In 1963, Murdock wrote a book titled Outline of World Cultures in which he states that culture can be divided into eight groups worldwide: Asia, Europe, Africa, Middle East, North America, South America, Russia and Croatia. The grouping pattern of Murdock gives another insight into the need for taking religion and form of government into consideration in addition to geographical factors. Having said this, exceptions would be Indonesia and Russia (to be excluded from Asia and Eurasia respectively) for reasons of religion and form of government. The countries in the Indochina region are attractive for investors as economically developing states that are rich in natural resources

\footnotetext{
${ }^{1}$ The term of 'emic' and 'etic.' taken from the linguistic terms "phonemic" and "phonetic" distinguish features that are overtly or consciously represented in a people's own cultural conceptions from features that are present but not a part of the overt or conscious local cultural conceptions. (Brown, 2004:2)
} 
and with nominal wage rates. The establishment of the Association of Southeast Asian Nations (ASEAN) Economic Community (AEC) in 2015 includes Brunei, Cambodia, Indonesia, Laos, Malaysia, Myanmar, Philippines, Singapore, Thailand, and Vietnam. The AEC 2015 is expected to usher in a new era of economic cooperation among the member countries. This also means that restrictions on investment and movement of workers among the AEC members have been relaxed. A steady increase in travel by tourists to these destinations has been noted.

\section{Myanmar: Southeast Asia's New Economy}

Republic of the Union of Myanmar is located in Southeast Asia, bordering India, Bangladesh, China, Laos, and Thailand. Myanmar faced a civil war from 1962 to 2011. Although the majority of people are poor, the country is rich in resources and working age population. The economy benefitted from rising investments, driven by inflows of foreign direct investment (FDI) and the government's infrastructure development efforts. According to a report by the Economist Intelligence Unit, FDI inflows were $\$ 3.2$ billion in the first 11 months of 2013-14, a huge rise from \$1.4 billion for the whole of 2012-13. Natural gas exports are also aiding the economy; estimates put Myanmar's natural gas exports at $\$ 3.6$ billion a year. Tourism has also benefitted from reforms. There were 2 million foreign tourist arrivals in Myanmar in 2013, almost double the number in 2012 (Barua, 2014:8).

Myanmar has suffered backlash from decades of sanctions by Western countries. However, even through this period Myanmar made efforts to reach out to the world. It had the opportunity to host the $27^{\text {th }}$ South East Asian (SEA) Games from 11 to 22 December 2013 and had a successful election in 2015. These steps seemed to indicate Myanmar's intentions of turning towards a market economy.

Thailand and Myanmar have promoted trade and investment for a long period, which continued through the years of Western sanctions. Thailand imported materials and energy. Meanwhile, Myanmar imported consumer goods. At present, Myanmar is following a policy of liberalization, which has led towards an open market economy. In general, Myanmar is now considered an interesting investment target, and in particular economic cooperation between Myanmar and Thailand is seen as having high potential.

This paper hopes to contribute first-hand knowledge on sub-regional culture by focusing on Thailand and Myanmar. Our point of departure rests on the key assumption that Thailand and Myanmar are both Buddhist countries, have a long historical relationship, and cultures based on religion. 


\section{Thai Cultural Universals}

Thai culture has several aspects that can be a magnet to attract tourists from other cultures. For example, a belief in or wish to explore the supernatural, mystical and magical powers, either for improving one's fortune or just out of a sense of adventure, can be a pulling factor. Several Thai tour and travel agencies share their experience that their business improved considerably if their itinerary included value-added activities related to mystical, magical, or even simply meditation items. This is also true of Thai travelers who travel to India with the hope of finding some supramundane answers for their prosperity and prestige; some go on a spiritual quest or seek alternative means to material solutions for relieving stress. Such practices are corroborated by the results of a survey on the travel habits of Thai people carried out in 2009 by the National Statistical Office in collaboration with the Ministry of Tourism and Sports (2009). The findings reveal that 18.7 percent of Thai people travel for pilgrimage to holy Buddhist places with Buddhist relics. On the other hand, the survey also showed that tourists from Laos come to Thailand for similar purposes of cultural tourism, which includes participation in auspicious occasions and festivals in addition to purchasing consumer goods. (Situation of Provincial Tourism Destinations in Ubon Ratchathani, 2011). According to the survey, people with the same religious backgrounds are also inclined to have similar cultural practices. The momentum of pull factors for travelers who start out on the grounds of similarities in culture can be built by adding novel items to the familiar items.

Eleven Thai cultural universals of tourism products were selected by a multidisciplinary team of experts from seven professions. These universals were used to get input from tourists regarding their perceptions and attitudes and to identify the stimulant factors that led tourists to make their decision to travel to Thailand. The results showed that 625 tourists in Chiang Mai, Sukhothai, Ayutthaya and Bangkok agreed on nine potential Thai cultural universals that would be effective for communicating tourism as a product. The nine potential Thai cultural universals included: cooking, weaving, ethnobotany, dancing, decorative art, folklore, therapy/medicine, wedding and education, respectively. Thai cultural universals have what it takes to appeal to potential tourists worldwide. However, they require appropriate packaging so they are easily recognizable, which will then result in attitudes that encourage travel decision-making as represented. The findings of this study enhance knowledge on tourism marketing and communication in Thailand, as well as other countries where cultural universals may be used to create awareness and promote tourism (Chokriensukchai, 2014). It has been observed, "What links world cities to one another is trade, commerce, and finance. What makes them different from one another is culture" (World Cities Culture Report, 2013). 


\section{Purposes of the Study}

The purposes of this research were:

(1) To study the travel behavior of Myanmar people

(2) To study media exposure of Myanmar people to Thai tourism

(3) To study the perception of Myanmar people regarding Thai cultural universals

(4) To study the relationship between information exposure to Thai tourism and perception of Myanmar people towards Thai cultural universals

(5) To study the relationship between perceptions of Thai cultural universals and demands of activities associated with the Thai cultural universals by Myanmar people

\section{Hypotheses}

Hypothesis 1: Thai tourism media exposure is associated with the perceptions of Thai cultural universals by Myanmar people at the level of statistical significance 0.05 .

Hypothesis 2: The perceptions of the Myanmar people regarding Thai cultural universals are associated with need-based activities related to Thai cultural universals.

\section{Research Methodology}

As no other study has been previously conducted providing a foundation from which to draw an empirical analysis, this investigation was purely an exploratory exercise utilizing qualitative inquiry and descriptive quantitative methods. The research investigation involved two phases designed to evoke responses that would accomplish the purposes of the study. Phase one utilized qualitative methods of conducting in-depth personal interviews and on-site observations in Myanmar, the country of the participants. The purpose of this initial phase was to understand the general situation, lifestyle, and media in Myanmar. From these findings it was the intent to develop a phase two partial survey instrument representative of travel behavior, media exposure induced behavior, exposure of tourists who visited Thailand, and awareness of Thai cultural universals and opinions of the Thai cultural universal to motivate visits to Thailand.

\section{Sample}

The sample for the preliminary interviews with individuals involved those in the trade and tourism sectors with commentary from scholars and journalists. 
The second group was a group of 385 people aged 20 years and over from varied professions. The survey was conducted in 2014 using a Cronbach's Alpha of 0.973 and the questionnaire was in Myanmar language. The data was collected from following areas: Yangon, Yankin Center, Junction Square, Union of Myanmar Federation of Chambers of Commerce and Industry (UMFCI), Myanmar Iwatany Company, Business School Student from Yangon University and South Okkala Township.

\section{Data Analysis}

The constant comparative method of content analysis was used to inductively analyze the transcribed tapes of the personal interviews and observation notes in order to discover basic information about general situation, lifestyle, and the media in Myanmar. Descriptive statistics of frequencies, percentages, and means were generated for the survey data. The results from an original smaller sample $(n=500)$ are not intended to be generalized to a larger population, but rather to provide a basis for further inquiry for testing hypotheses with larger samples in order to make generalizations.

\section{Results}

The survey sample was composed of 130 males $(33.77 \%)$ and 255 females $(66.23 \%)$. Of all the participants, 196 were in the age range 21-30 years $(50.91 \%), 245$ had the education level of bachelor's degree $(63.64 \%)$, 283 were contractors or employees of private companies $(73.51 \%)$. and 173 had revenues ranging from less than or equal to 36 US dollars, or 10,000 Baht $(44.94 \%)$.

\section{Travel Behavior of Myanmar Citizens}

The results of the survey showed that the majority of people from Myanmar travel in general 1-2 times annually (44.68 \%). The instance of traveling abroad 1-2 times a year occurs at a lower rate $(32.21 \%)$, however there are more who may have the opportunity to travel $(36.10 \%)$. most popular destinations $(62.34 \%)$, often travel with families $(42.60 \%)$, like visiting natural attraction $(60.26 \%)$.

\section{Thai Tourism Media Exposure of Myanmar}

The major sources of travel information as shown below in Table 1 were acquaintances or people who had already had exposure to Thai tourism 
information: personal (57.14\%), internet (28.31), Newspaper (8.83) Television (4.94) and Radio (0.78), respectively.

Table 1. Number and Percentage of Category of Media Exposure of Myanmar People to Thai Tourism

\begin{tabular}{|c|c|c|c|}
\hline \multirow{2}{*}{ Media Channel } & \multicolumn{3}{|c|}{ Level of Exposure } \\
\cline { 2 - 4 } & Number & Percentage & Ranking \\
\hline Television & 19 & 4.94 & 4 \\
\hline Radio & 3 & 0.78 & 5 \\
\hline Personal & 220 & 57.14 & 1 \\
\hline Newspaper & 34 & 8.83 & 3 \\
\hline Internet & 109 & 28.31 & 2 \\
\hline Overall & 385 & 100.0 & \\
\hline
\end{tabular}

\section{Activities Related to Thai Cultural Universals}

The nine Thai cultural universals include: Thai weaving, Thai decorative art, Thai ethno-botany, Thai cooking/food, Thai dancing, Thai folklore, Thai education, Thai wedding and Thai medicine/therapy (Chokriensukchai, 2014). The survey revealed that most Myanmar people have knowledge of Thai food, followed by Thai decorative arts and Thai weaving as shown in Table 4.

Table 2. Perception of Thai Cultural Universals within the International Tourism Communications

\begin{tabular}{|l|c|c|c|}
\hline \multicolumn{1}{|c|}{ Thai Cultural Universals } & Number $^{*}$ & Percentage & Ranking \\
\hline Weaving & 296 & 76.88 & 3 \\
\hline Decorative art & 311 & 80.78 & 2 \\
\hline Ethno-botany & 168 & 43.64 & 7 \\
\hline Cooking/food & 358 & 92.99 & 1 \\
\hline Dancing & 265 & 68.83 & 4 \\
\hline Folklore & 253 & 65.71 & 5 \\
\hline Education & 226 & 58.70 & 6 \\
\hline Thai Wedding & 151 & 39.22 & 9 \\
\hline Medicine/therapy & 162 & 42.08 & 8 \\
\hline
\end{tabular}

*Can choose more than one answer.

\section{Popular Activities within the Framework of Thai Cultural Universals}

Regarding the preferred activities within the framework of the nine Thai cultural universals, the survey revealed that the highest demand was for activities within the field of education, in particular short term college or school classes $(\bar{x}=3.60)$, followed by courses in career $(\bar{x}=3.42)$ and visits or meditation as a means of cure for ailments $(x=3.38)$, respectively, as shown in Table 3. 
Table 3. Popular Activities under the Framework of Thai Cultural Universals

\begin{tabular}{|c|c|c|c|}
\hline Thai Cultural Universals Activity & $\bar{x} *$ & S.D & Ranking \\
\hline \multicolumn{4}{|l|}{ Thai Weaving } \\
\hline $\begin{array}{l}\text { Observe traditional furniture making for work } \\
\text { places/house decoration }\end{array}$ & 3.04 & 1.13 & 18 \\
\hline \multicolumn{4}{|l|}{ Thai Decorative art } \\
\hline Observe traditional methods of art design & 3.31 & 1.12 & 5 \\
\hline $\begin{array}{l}\text { Observe pottery making for work places / house } \\
\text { decoration }\end{array}$ & 3.02 & 1.06 & 19 \\
\hline $\begin{array}{l}\text { Observe traditional ways of weaving items for } \\
\text { daily use }\end{array}$ & 3.06 & 1.12 & 17 \\
\hline \multicolumn{4}{|l|}{ Thai Ethno-botany } \\
\hline $\begin{array}{l}\text { Visit crop fields and crop processing facilities for } \\
\text { skin care }\end{array}$ & 3.24 & 1.19 & 6 \\
\hline $\begin{array}{l}\text { Visit the herb processing facilities for stress relief } \\
\text { and spa }\end{array}$ & 3.33 & 1.28 & 4 \\
\hline \multicolumn{4}{|l|}{ Thai Cooking } \\
\hline $\begin{array}{l}\text { Participate in traditional Thai cuisine } \\
\text { workshop/show }\end{array}$ & 3.18 & 1.25 & 9 \\
\hline $\begin{array}{l}\text { Participate in contemporary Thai cuisine } \\
\text { workshop/show }\end{array}$ & 3.11 & 1.18 & 13 \\
\hline $\begin{array}{l}\text { Participate in Thai cuisine for culinary art } \\
\text { workshop/show }\end{array}$ & 3.12 & 1.23 & 12 \\
\hline $\begin{array}{l}\begin{array}{l}\text { Participate in of Thai fusion cuisine } \\
\text { workshop/show }\end{array} \\
\end{array}$ & 3.00 & 1.20 & 20 \\
\hline \multicolumn{4}{|l|}{ Thai Folklore } \\
\hline $\begin{array}{l}\text { Participate in traditional practices for improving } \\
\text { ones fortune }\end{array}$ & 3.09 & 1.25 & 15 \\
\hline $\begin{array}{l}\text { Observe traditional architectures such as } \\
\text { traditional Thai houses }\end{array}$ & 3.20 & 1.12 & 7 \\
\hline \multicolumn{4}{|l|}{ Thai Education } \\
\hline $\begin{array}{l}\text { Attend short courses in universities or schools in } \\
\text { Thailand }\end{array}$ & 3.60 & 1.23 & 1 \\
\hline Attend professional or career related courses & 3.42 & 1.26 & 2 \\
\hline Attend Thai language courses & 3.06 & 1.25 & 16 \\
\hline \multicolumn{4}{|l|}{ Thai Medicine } \\
\hline Explore alternative Thai medical treatment & 3.13 & 1.27 & 11 \\
\hline Explore Thai massage therapy & 3.10 & 1.29 & 14 \\
\hline Explore meditation therapy & 3.38 & 1.21 & 3 \\
\hline Explore rites and ritual therapy & 3.15 & 1.25 & 10 \\
\hline
\end{tabular}

Note: *Report only those $\bar{x}>3.00$ 


\section{The Hypothesis Test}

Hypothesis 1. Thai Tourism Media Exposure is associated with the Perception of Thai Cultural Universals of Myanmar People at the level of Statistical Significance. 05

\begin{tabular}{|c|c|c|c|c|c|c|}
\hline \multirow{2}{*}{$\begin{array}{c}\text { The perception of } \\
\text { Thai Cultural } \\
\text { Universals }\end{array}$} & \multicolumn{6}{|c|}{ Thai Tourism Through Media Exposure } \\
\cline { 2 - 7 } & Television & Radio & Personal & Newspaper & Internet & $\begin{array}{c}\text { Over } \\
\text { all }\end{array}$ \\
\cline { 2 - 8 } & $.325^{*}$ & $.245^{*}$ & $.653^{*}$ & $.411^{*}$ & $.622^{*}$ & $.563^{*}$ \\
\hline
\end{tabular}

*A statistically significant level .05

The study result rated the perception of Thai cultural universals through media exposure at a statistically significant level of $.05(\mathrm{r}=.563)$. Media channels associated with this exposure to Thai cultural universals included: personal media, internet, newspaper, television and radio, and the level of statistical significance was indicated to be $.05(\mathrm{r}=.653, \mathrm{r}=.622, \mathrm{r}=.411, \mathrm{r}$ $=.325$ and $\mathrm{r}=.245$, respectively). Therefore it can be assumed that the perceptions of Myanmar people in regards to Thai cultural universals has a degree of dependency on media exposure.

Hypothesis 2. The Perception of Myanmar on Thai Cultural Universals is associated with need based Activities related to Thai Cultural Universals

\begin{tabular}{|l|c|c|c|}
\hline \multirow{2}{*}{$\begin{array}{c}\text { The perception } \\
\text { of Thai Cultural Universals }\end{array}$} & \multicolumn{3}{|c|}{$\begin{array}{c}\text { Desired Activities Within the Range of Thai } \\
\text { Cultural Universals }\end{array}$} \\
\cline { 2 - 4 } & Value & df & Sig. \\
\hline Weaving & 72.732 & 4 & $.000^{*}$ \\
\hline Decorative art & 18.511 & 4 & $.001^{*}$ \\
\hline Ethno-botany & 28.985 & 4 & $.000^{*}$ \\
\hline Cooking/food & 61.726 & 4 & $.000^{*}$ \\
\hline Dancing & 17.257 & 4 & $.002^{*}$ \\
\hline Folklore & 35.220 & 4 & $.000^{*}$ \\
\hline Education & 72.29 & 4 & $.000^{*}$ \\
\hline Thai Wedding & 28.140 & 4 & $.000^{*}$ \\
\hline Medicine/therapy & 51.057 & 4 & $.000^{*}$ \\
\hline
\end{tabular}

*A statistically significant level. 05 .

The result showed that Thai cultural universals perception matched the desired activities of Myanmar people at the statistically significant level .05. 


\section{Results}

\section{Media Utilization in Communication Tourism}

Although Myanmar has opened the country and started investing in infrastructure, the survey found that Myanmar still relies on traditional media exposure, such as personal media, to communicate about Thai tourism. If Myanmar does open up to other countries apart from Thailand, the Myanmar people may resort to other news sources. As many migrant workers move from Myanmar to Thailand they can be a reliable source for people back home to gain information on Thai tourism.

As person-to-person communication can take place immediately and is perceived to be trustworthy, the Myanmar migrant workers to Thailand can be a valuable resource for imparting information on Thai tourism to people back home. In addition, survey results revealed that the interviewees used certain Internet media. Thus information about Thai tourism can be disseminated through personal media in conjunction with the Internet. The media type with a low or negligible exposure rate was radio, as it provided little or no content on Thai tourism. Furthermore, radio is not a popular form of media communication among Myanmar people. One reason could be that it is under the control of the Government of Myanmar, despite the fact that censorship is said to have been lifted since 2011 (Kyaw Min Swe, 2013). The content of the radio programmes does not cover tourism either.

\section{Perception of Thai Cultural Universals of Myanmar}

The survey found that Myanmar people are familiar with Thai food. People often think of food as one of the four items necessary for subsistence. Also food is a global piece of culture that exists in every society. "From the tourist experience perspective, food consumption in tourism can be conceptually distinguished into 'supporting consumer experience' and 'peak touristic experience" (Quan and Wang, 2004). This distinction is based on food consumption's relationship to tourists' daily routine, whether it is contrasting, intensifying, or extending the daily routine experience" (Mak, Lumbers and Eves, 2012:178).

The survey results are also in line with the results of the survey research center in Bangkok (2009), which showed that the five top attractions for foreign tourists to Bangkok, Thailand included: food, archaeological sites, hospitable people, culture and art, and shopping centres. The result is corroborated by several other surveys in recent years, including the Wiens report by CNN travel (Wiens, 2016), which is quoted below:

"40 Thai foods we can't live without"

In celebration of Bangkok's fantastic cuisine and the restaurants that have perfected it, we've rounded up 40 of the Thai dishes we couldn't imagine 
living without. Some are world famous, others are more obscure, but they're all worth trying, at least once.

In addition, Thailand has focused on the issue of building awareness related to public relations for quite a long time. Thai food in particular has been a major pull factor for tourists to visit Thailand. Possible contributing factors regarding Thai food's attraction could include: unique presentation, taste, aroma and reasonable pricing. To experience authentic Thai cuisine, visitors must come to Thailand.

One of the other Thai cultural universals that attracted Myanmar people to Thailand was educational activity. With the recent opening up of Myanmar to the world, movements towards an open market have resulted in more job opportunities that require a certain level of qualifications, knowledge and skills. As such, there is a substantial section of the population in Myanmar that is now seeking an upgrade to education. Survey results from open-ended questions revealed that several interviewees also wanted to visit Thailand because it is primarily a Buddhist country.

\section{Recommendations}

\section{Using New Media in the Old Way}

"... history shows that when new media are introduced communicators tend to use them in the same way that they used the old media. For example, journalists first used television just as they used radio. Accustomed to reading news on the radio, they continued to read the news on television without making use of the pictures that the new medium allowed"

(Grunig, 2009)

This seems to be applicable to the way communication is used in Myanmar, which has only recently opened up to new media. Myanmar still largely uses traditional forms of old media and, even though new media has been introduced, various forms act in tandem with old media. New media may even be used in the ways of the old media. For example, the webpage could be used merely as a means of providing detailed information about a product or simply used in place of a phone for making it a two-way communication. It also may act as a replacement of a letter by email.

\section{Personal (human) Media}

Although Myanmar is opening the country and has invested in infrastructure, the survey found that Myanmar is still languishing in the era of old media, such as personal media and billboards, when it comes to disseminating information on tourism. The logic behind this may be that it is easily accessible. Personal media includes relatives and friends who have the 
advantage of reliability and through whom two-way communication is immediately possible. Tourism is therefore likely being communicated through this type of media to the target groups in Myanmar. Therefore, regarding promotion of tourism in Myanmar, there is a need for updated and appropriate use of new media for communicating about tourism in Thailand, in addition to the existing old media.

\section{Communicating Thai Cultural Tourism to the People of Myanmar}

Thai cultural universals perceptions showed that interviewees showed interest in short term study in Thailand. With the opening up of Myanmar, the Myanmar people are showing interest in learning about the culture and language of their neighbouring country. They did not express interest in spending much time, however. Taking these findings into consideration, the communication content for promoting tourism in Thailand should focus on what the Myanmar people are familiar with and what they know about Thai culture. Specifically, it appears that the initial focus should be on introducing travel programmes that include short or formal degree courses directed towards professional and career-building subjects.

Another area that holds potential is the common factors of being Buddhist countries and also having a shared history. The tourism could use the common philosophy and history as pull factors, which are attractive to the Myanmar people.

The survey found that the people of Myanmar are attracted by nature. Thailand has a varied range of natural attractions, from the hilly northern areas to the seaside with breathtaking beaches. Creating perceptions of these natural beauties of Thailand can be a strong pull factor for Myanmar people.

The survey also revealed that there are areas of caution that Thailand needs to take into serious consideration. One problem is the habitual pattern of deriding one's neighbouring countries, which is commonly found in most cultures. However, keeping modern technology in mind, specifically new media, two things have to be kept in mind: historical events that have given rise to conflicts, and holding the neighbouring country in contempt (as being poorer and underdeveloped). Moreover, the political situation and unrest in Myanmar has to be dealt with sensitively and cautiously to avoid causing harm.

In addition, the survey results also caution about the perceived image of Thailand in Myanmar. This includes such negative information as dangers of human trafficking, HIV/AIDS, and the sex trade. These factors may not give a favourable image to tourists, not only from Myanmar but also from other countries. 


\section{Bibliography}

Alberti FG, and Giusti J (2012) Cultural heritage, tourism and regional competitiveness: The Motor valley cluster. City, Culture and Society 2: 261-273.

Bangkok University Research Center. (2009) Survey on satisfaction needs of foreign tourists to visit Bangkok. Available at: http://www.bangkokpoll.bu.au.ac.th/poll/ result/doc/poll452.pdf

Barua A (2014) Myanmar: A long and challenging road ahead. Asian Pacific Economic Outlook: China Japan Myanmar Singapore : 8-10. Deloltte University Press. Available at: http://d2mtr37y39tpbu.cloudfront.net/wp

Brown DE (1991) Human universals. New York: McGraw-Hill.

Brown DE (2004) Human Universals, Human Nature \& Human Culture. Daedalus 133: 47-54.

Cleaveland A A Craven J, and Danfelser (1979) Universals of culture New York: Center for Global Perspectives.

Chokriensukchai K (2014) Thai cultural universals and tourism communication. Media Asia 41: 151-158.

Cohen E (1979) A phenomenology of tourist experiences. Sociology 13: 179-201.

Cooke P, and Lazzeretti L (2008) Creative Cities, Cultural Clusters and Local Economic Development. Cheltenham: Edward Elgar.

Fodness D, and Murray B (1999) A model of tourist Information search behavior. Journal of Travel Research 37: 220-230.

Grunig JE (2009) Paradigms of global public relations in an age of digitalization. Prism 6. Available at: http://www.prismjournal.org/fileadmin/Praxis/Files/global PR/GRUNIG.pdf

Kotler P, and Armstrong G (2001) Principles of Marketing. 9th ed. New Jersey: Prentice Hall.

Kyaw Min Swe (November 2013) Lecture Presented on Visiting the Office of Myanmar Newspaper in Kanbalu, Myanmar.

Lazzeretti L, Capone F, and Cinti T (2011) Open innovation in city of art: The case of laser technologies for conservation in Florence. City, Culture and Society 2: $159-168$.

Lévi-Strauss C (1966) The Savage Mind. Chicago: University of Chicago Press.

Littrell MA (1997) Shopping experiences and marketing of culture to tourists. In: Robinson M, Evans N, and Callaghan P (eds.) Tourism and culture: Image, identity and marketing. Sunderland: University of Northumbria, Centre for Travel and Tourism.

MacCannell D (1999) The tourist: A new theory of the leisure class. Berkeley: University of California Press.

Mak AHN Lumbers M, and Eves A (2012) Globalisation and food consumption in tourism. Annals of Tourism Research 39: 171-196.

Mandala Research (2013) U.S. Department of Commerce, US Travel Association. Available at: from http://www.AmericansForThe Arts.org

Ministry of Tourism and Sports (January 7, 2009) Tourist situation report for January 7. Available at: http://secretary.mots.go.th/policy/more_news.php?cid=351 (in Thai).

Murdock GP (1945) The common denominator of culture. In: Linton R (eds.) The science of man in the world crisis. New York: Columbia University Press.

Power D, and Scott A (eds.) (2004) Cultural industries and the production of culture. London: Routledge. 
Quan S, and Wang N (2004) Towards a Structural Model of the Tourist Experience: An Illustration from Food Experience in Tourism. Tourism Management, 3: 297-305.

Rabaneda RA (2012) Cultural events and cultural heritage in times of crisis: A case in Catalonia. In: Lyck L, Long P, and Grige AX (eds.) Tourism, festivals and cultural events in times of crisis. Vanløse: Frederiksberg Bogtrykkeri, 25-36.

Richards G (Ed.) (2011) Cultural tourism: Global and local perspectives. New York: Routledge.

Richards G (1996/2005) Cultural tourism in Europe. Tilburg: ATLAS. Available at: www.tram-research.com/cultural_tourism_in_europe.PDF

Rogers EM (2003) Diffusion of innovations (5th ed). New York: Free Press.

Situation provincial tourism destinations in Ubon Ratchathani. (2011). Available at: http://www2.tat.or.th (in Thai)

Smith MK (2009) Issues in cultural tourism studies. London: Routledge. Available at: https://loomen.carnet.hr/.../Melanie_Smith-Issues_in_Cultural_Tourism_...

Spoehr A (1965) Foreword. In: Murdock PG, Culture and society: Twenty-four essays. Pittsburg: University of Pittsburgh Press .

Wiens M (January 4, 2016) Report on CNN travel. Available at: http://travel.cnn.com.

World Cities Culture Report. (October 2013) Cited in T. A. Hutton, 2016. Cities and the cultural economy. New York: Routledge

WTTC (2016). Travel \& Tourism Economic Impact 2015 Thailand. Available at: http://www.wttc.org 